\title{
La fuerza oscura de las estadísticas
}

\section{Dr. LuIS BorTeSI LONGHI}

Docente Asociado de la Facultad de Ciencias Contables

\section{RESUMEN}

Tiene razón el sabio Salomón y también la tiene cuando dice: "mejor encontrarse con una osa a la cual le han robado sus cachorros, que con un fatuo en su necedad". (Proverbios XVII, 12)

Los fatuos en su necedad lo son en número infinito y son aquellos que se arrogan supremacía porque se creen "instalados" en lo que llaman la era del conocimiento, la cual si fuera sometida a prueba con rigurosidad no soportaría ningún análisis porque consiste en una suma de datos cuantitativos que no aportan casi nada a la calidad de la cultura. Encontrarse con un necio arrogante es una prueba muy difícil para la paciencia. Era verdaderamente sabio el sabio Salomón.

El presente escrito está destinado a reflexionar sobre la labor y alcance de las estadísticas y los que las profesan que son los estadisticos.

La objeción principal que se le imputa a la estadistica es que se privilegia el dominio de la cantidad pura ignorándose completamente lo más elevado que es, siempre, el aspecto cualitativo. Se toman en cuenta unidades numéricas que se asumen arbitrariamente idénticas entre todas.

Palabras clave: Estadística, probabilidades estadísticas, influencia numérica de la Estadística. 


\section{INTRODUCCIÓN}

La economía descansa en tres principales ciencias que son las columnas de su estructura: la Contabilidad, la Psicología y la Estadística.

Merecen mención aparte la econometría y la matemática financiera. En cuanto a la primera, hay que decir que no ha tenido éxito porque reducir el fenómeno económico a la matemática pura no es posible porque eso equivale a desconocerle el aspecto vital, cual es el comportamiento humano. Las matemáticas financieras ocupan un campo particular que funciona aparte y cuyo nivel de abstracción ha derivado en modernas fórmulas de extraordinaria sofisticación.

Si se recurre a la analogía, se podría decir que la Contabilidad es para la Economía como el Sol (o como el oro); la Psicología como la Luna (o como la plata); y la Estadística como Saturno (o el plomo).

La Contabilidad sí puede, con todo derecho, ser reconocida como una ciencia verdadera por su rigor y exactitud y corresponde a un principio universal que es su ley: la equivalencia en la complementariedad de los opuestos (activo y pasivo).

La Psicología se ha convertido en el ingrediente principal de la actividad economía y financiera moderna, ya que el éxito (o fracaso) obedece al factor confianza, credibilidad, optimismo, o viceversa, tanto a nivel micro, como por ejemplo en el caso del estudio del comportamiento del consumidor, como en el macro que depende de la fe en el futuro, inversión y percepción favorable de la política económica.

El presente escrito está destinado a reflexionar sobre la labor y alcance de las estadísticas y los que las profesan que son los estadísticos.

\section{DISCUSIÓN PRINCIPAL IMPUTADA A LA ESTADÍSTICA}

La discusión principal que se le imputa a la estadística es que se privilegia el dominio de la cantidad pura ignorándose completamente lo más elevado que es siempre el aspecto cualitativo. Se toman en cuenta unidades numéricas que se asumen arbitrariamente idénticas entre todas.

Según el punto de vista científico moderno solamente tiene condición "real" aquello que es evidente por la percepción de los sentidos y que, a su vez, es susceptible de ser medido. Este prejuicio del cual se nutre principalmente el método científico moderno ignora por completo, y en ocasiones se mofa, del mundo más rico de la existencia y de la Realidad que es la metafísica, que significa literalmente "más allá de la física"

El grado de "realidad" de la manifestación universal está precisamente en razón inversa con la materialidad, es decir con la pertenencia al mundo sensible. Es así que el Espíritu puro ocupa una jerarquía superior al cuerpo; pero todas estas consideraciones entran en conflicto con los métodos estadísticos porque se pretende, por ejemplo, medir la capacidad intelectual; o pesar el cerebro de Alberto Einstein para determinar cuántos gramos de ventaja llevaba el sabio con respecto al promedio de la especie humana.

Todo aquello que no se puede medir o pesar no es "real" según los preceptos del Reino de la Cantidad. Pero todos saben que no se puede pesar el alma o tener comprobación sensible de un pensamiento. Son estas las contestaciones que es procedente interponer contra la Estadística.

La premisa en que se apoya la estadística es esta: todo se puede medir, esa medición se puede reducir su expresión más simple, es decir, a la unidad y las expresiones nu- 
méricas reducidas a la unidad, son idénticas entre sí.

Pero ese supuesto no solamente es falso; sino que aplicado a la vida humana, resulta monstruoso, puesto que le atribuye a toda la especie una nivelación en el más bajo estado de uniformidad.

¿Cómo es posible que se afirme que un individuo es equivalente a otro si nadie tiene la impronta digital igual; tampoco el timbre de la voz; y es distinto el ADN de cada ser humano?

$\mathrm{Ni}$ siquiera una piedra es idéntica a otra. Esto lo demostró el Barón Gottfried Wilhelm von Leibnitz, eximio matemático descubridor del cálculo infinitesimal y de la Teoría de los Límites, con su "Principio de los indiscernibles", donde se evidencia que sí dos individuos fueran idénticos ya no serían dos, sino uno solo en realidad.

Cuando, como sucede en nuestros días, está presente la filosofía de vida que se basa en el principio del igualitarismo, se derivan consecuencias nefastas de materialismo progresivo que erosiona la política y la educación, ya que toda masificación es por naturaleza tendiente a lo más grosero.

Aunque las estadísticas evidentemente se basan en puras cantidades, tienen la pretensión de referirse también a aspectos cualitativos tratando de introducir elementos distintivos mediante el uso de ponderaciones aunque todas derivan de cantidades y sus resultados acaben redundando a su vez en guarismos cuantitativos nuevamente. Se habla así de la "calidad de vida" y para jerarquizarla se tiene en cuenta la renta per cápita, el consumo de bienes conspicuos y en general el nivel económico y presupuestario de las familias. Pero tal como se puede comprobar cuando se estudia el esquema priorizado de las necesidades humanas, en la mayoría de los casos aún teniendo un elevado presupuesto económico las familias carecen de otro tipo de disfrute como es claro en la ausencia de paz y tranquilidad. La necesidad más imperativa y aguda del hombre es, sin duda alguna, el afecto, el ser comprendido y estimado; nada tiene eso que ver con aspectos cuantitativos de la existencia. Por otro lado, y poniendo un ejemplo más doméstico, se tiene que considerar que tampoco tiene fundamento decir que un dólar es idéntico a otro porque una moneda no tiene la misma capacidad cancelatoria, digamos en Nueva York, que en un país de África.

En materia de cantidades y vulgaridades, se sostiene en el dominio político un postulado vigente y aberrante como es el de que "la mayoría manda" no importando las calificaciones que reúne cada uno dentro del grupo.

Otra consecuencia muy grave que se produce cuando se está sometido al reino de la cantidad se experimenta en el sector educación: puesto que se presume que todos son iguales, la "educación" debe ser "única, general y obligatoria”. No cuentan las aptitudes diferenciadas que seguramente tienen los estudiantes.

En un ambiente donde se considera que todos los alumnos son sustancialmente iguales, es casi imposible estimular la introspección vocacional. Existe, además, una manía por sacar porcentajes para explicar fenómenos cualitativos. Por ejemplo, se afirma que "como producto del crecimiento de nivel educativo de la población, los niveles educativos de la PEA están en constante crecimiento. En el ańo 1993, el 8.9\% de la PEA tenía educación superior universitaria completa, aumentando al $13.7 \%$ para el año 2000. En un país donde existen 80 universidades absolutamente heterogéneas y que amenazan seguir pululando y donde tan solo en número de un dígito podría clasificarse como univer- 
sidades verdaderas ¿̨nos dice algo el porcentaje arriba mencionado?

El igualitarismo degrada a la humanidad a los más bajos estamentos de la existencia donde la diferenciación es imperceptible; se la trata en función de números simples como a las especies indiferenciadas como son las hormigas, las abejas o el cardumen.

Volviendo la atención a las estadísticas, recordemos que el año 1654, el Caballero de Mére, jugador y matemático, propuso a Blas Pascal un problema relativo a la chance para ganar en un juego de dados. Pascal transmitió el acertijo al matemático Fermat, y de la correspondencia entre ambos surgió lo que posteriormente ha llegado a ser la moderna teoría de las probabilidades que constituye el fundamento de la estadística matemática.

Uno de los principios que encontramos en la ley de los grandes números es el que sostiene que mientras mayor sea el registro de veces de un fenómeno, la determinación de probabilidades debe ser más precisa (siempre teniendo en cuenta como supuesto básico que un fenómeno es igual a otro), lo que demuestra que los propios estadísticos, al aspirar modestamente a probabilidades, reconocen que la naturaleza de su ejercicio no es científico si se habla con rigor.

\section{Propósitos que debería cumplir el conocimiento estadístico}

1. Proporcionar base (la "data") para conocer "la realidad".

2. Extraer conclusiones que permitan algunas predicciones.

\section{Principales instrumentos que disponen los estadísticos:}

Son tres, a saber: el cálculo de las Medias, por ejemplo la media armónica, la geomé- trica, etc.; un segundo instrumento es el mecanismo de Ponderación; y el tercero es la obtención y el Análisis de Muestras.

Dijo un bromista que sí un hombre mete la cabeza en el congelador y los pies en el horno, la temperatura media de su cuerpo sería la correcta.

La muestra presupone que la partícula es perfectamente homóloga al universo y que, por lo tanto, ese micro fenómeno podrá ser reproducido a nivel general. Esto puede resultar cierto a condición de un altísimo nivel de estandarización, pero es un hecho incontestable que estaríamos en la perspectiva de la cantidad pura.

La ponderación es la técnica para compensar con cantidades diferenciadas el defecto que en cuestión de calidad acusa el método estadístico. Con la ponderación (literalmente "dar peso") se debería cuantificar las cualidades. (No se trata de un juego de palabras).

Las predicciones sobre el clima, por ejemplo, son extrapolaciones de series numéricas que debidamente estudiadas con los ajustes de las medidas y la ponderaciones anticipan el comportamiento que probablemente seguirá la tal serie. Mientras más larga es la serie, a la que se le llama científicamente "serie histórica", mayor deberá ser su exactitud predictiva.

Las aplicaciones prácticas de la estadística son múltiples y se puede, a este propósito, seleccionar como un acertado ejemplo a las compañías de seguros que trabajan en base al cálculo de índices de siniestralidad. También los estudios de mercado utilizan muestras como elemento indispensable en el ejercicio del comercio moderno.

Pero lo cierto es que la confianza que se le puede dispensar a las proyecciones estadísticas es cada vez menor porque los acontecimientos a nivel planetario se des- 
envuelven con tal rapidez que las sorpresas son cada vez más frecuentes y en su mayoría desagradables desbordando todas las previsiones y probabilidades. Esto resulta palmario en dos campos distintos: en los descubrimientos que convierten todo lo anterior en obsolescente y en lo que se llama "riesgo país" que representa tal vez la mayor preocupación mundial desde el 11 de septiembre del año 2001.

En los círculos intelectuales, se piensa que la investigación es un trabajo que consiste en descubrir la verdad examinando un hecho y profundizándolo hasta extraer, mediante esfuerzo intelectual, conclusiones y recomendaciones respecto de él. Pero no siempre es así (a decir verdad casi nunca). En innumerables circunstancias se tiene una idea preconcebida y el investigador busca y selecciona en todas las fuentes que descubre y consigue datos que le sirven para apoyar su teoría. Por lo tanto, la teoría precede a la "investigación" y la Estadística compone el material para "demostrar" lo que estaba anteladamente previsto. Tanto esto es verdad que se han visto casos en que con las mismas fuentes se pretende demostrar pensamientos contradictorios y a veces abiertamente antitéticos.

Otra observación digna de remarcarse es que los que trabajan registrando estadísticas incurren en gruesas aproximaciones porque, si no las inventan, las "estiman" ya que es prácticamente imposible captar con datos numéricos todo lo que acontece en todos los sectores y regiones, en cuyo supuesto las variables serian infinitas. Algunos profesionales se refieren a estas inexactitudes empleando el eufemismo "discrepancia estadística" (statistic discrepancy). Otros hablan de "margen de error".

Pero, independientemente de todo lo anterior, el "pecado" más temible a que nos ha inducido la estadística ha sido el de modificar el concepto de lo normal. Es esta una gran desgracia, imputable a la estadística, que origina que la mentalidad moderna, sobre todo la de los jóvenes, repute de normales hechos mayoritarios que son una lacra para la humanidad. Según el criterio contemporáneo es normal probar drogas, estar motivado solo por el lucro, la violencia y el sexo en televisión, el desenfreno y la "diversión" en las discotecas, la pornografía, la agresividad, que recibe a veces la denominación de "competitividad", etc.

Lo NORMAL, en su sentido legítimo, es aquello que procede según las NORMAS que están consignadas en la doctrina, la Cristiana, por ejemplo, y todo aquello que se le opone es abiertamente ANORMAL aunque lo practique una enorme mayoría, y es un hecho innegable que la conducta que registra la estadística de las preferencias masivas demuestra en la actualidad la decadencia y la disolución de la espiritualidad, la religión y la cultura.

Otro maleficio que se perpetra utilizando estadísticas está configurado en las encuestas y el "raiting".

Se trata del más vulgar y peligroso procedimiento para auscultar periódicamente "la opinión pública" y obtener porcentajes de aprobación y de prestigio que inoculan morbosamente el virus de la inestabilidad y de la desesperación para ser aprobados, no importa a qué precio. El vicioso combustible de las encuestas populares es el escándalo, que es el factor que "jala más raiting”.

Las encuestas dirigidas a la "opinión pública” suelen estar estructuradas para demostrar hechos previstos intencionalmente de antemano, de la manera más superficial e injusta que se pueda imaginar. Es así que se interroga en plena calle a cualquiera, a un vendedor ambulante o a un analfabeto, qué 
opina, por ejemplo, acerca del desempeño del ministro de economía. Y la opción es "aprueba" o "desaprueba". Las respuestas, que son puramente intuitivas y siempre motivadas por un rumor o contagio general, se utilizan para demoler la gestión del ministro, cuando la verdad es que nadie sabe cómo está trabajando en su intimidad el ministerio ni tampoco aquel "que emite su opinión” tiene la mínima competencia profesional sobre la materia sobre la cual tiene la audacia de pronunciarse.

Tales son los preceptos que rigen el reino de la cantidad y a su principal artífice: la fuerza oscura de las estadísticas.

Una de las paradojas matemáticas más antiguas es aquella del árabe rico que al morir les dejó a sus tres hijos una cuadra con 17 hermosos caballos, especificando que habían de repartirla en la siguiente forma: al mayor la mitad de los caballos, al siguiente un tercio y al menor un noveno. Los jóvenes herederos estaban desesperados, ya que evidentemente no podían repartir los $17 \mathrm{ca}$ ballos de esta manera sin la colaboración del carnicero. Buscaron finalmente los consejos de un sabio anciano que prometió su ayuda. Al siguiente día se presentó el venerable Sheick en la cuadra llevando de las riendas un caballo de su propiedad. Lo juntó a los otros 17 y los hermanos ya podían proceder al reparto. El mayor se llevó la mitad de los dieciocho, es decir 9. El segundo obtuvo un tercio es decir 6 y el menor un noveno o sea dos. Cuando ya se hubieron llevado los 17 primeros caballos, el anciano montó el suyo y se marchó.

\section{CONCLUSIONES}

La rigurosidad de las estadísticas en base a las frecuencias numéricas son secuencias que no analizan directamente el aspecto cualitativo de un fenómeno, sino en toda su extensión se basa en probabilidades que no caracterizan su capacidad analizadora como método científico.

Las secuencias o acciones repetitivas de un fenómeno no anticipan con exactitud su comportamiento, ni la estadística podría explicar si se observase una modificación del mismo, por lo que se comprueba que las secuencias estadísticas no serían resultados lógicos, sino meramente predictivas.

Las encuestas dirigidas a la "opinión pública” suelen estar estructuradas para demostrar hechos previstos intencionalmente de antemano, de la manera más superficial e injusta que se pueda imaginar.

\section{REFERENCIAS}

Ambrosi, Hugo O. La verdad de las estadísticas.

BACCHINI, Roberto D. Estadistica, probabilidad e inferencia utilizando Microsoft Excel y Spss.

Lahoz-Beltrá, R.; Ortega-Escobar, V.; Fernández Montraveta, C. Métodos estadísticos del comportamiento.

Mason, Robert D. Estadistica para administración y economía. 